\title{
articles
}

\section{Cannabis use and abuse correlates in a homogeneous South African schizophrenia population}

L Koen, MB ChB, MMed (Psych), PhD

R Jonathan, $M B C h B$

D J H Niehaus, MB ChB, MMed (Psych), FCPsych, DMed Ngaphakathi Workgroup, Department of Psychiatry, Stellenbosch University and Stikland Hospital, W Cape

Objective. Worldwide, cannabis is the most widely used illicit substance, and it has been identified as a correlate in schizophrenia samples for poorer symptomatic and functional outcomes in many international studies. The object of this retrospective study was to identify the prevalence of cannabis use/abuse and the demographic and clinical correlates therefor in a large homogeneous South African schizophrenia population.

Methods. As part of a large genetic study, 547 subjects with a diagnosis of schizophrenia were recruited. Demographic and clinical data were collected and each participant underwent a urinary drug screen. Use/abuse of cannabis was defined as using cannabis more than 21 times in a single year. Subjects with and without cannabis use/abuse were statistically compared.

Results. Significant differences between the two groups were found in terms of gender, marital status, age of onset of schizophrenia, number of hospitalisations and relapses, alcohol abuse, smoking, the Scale for the Assessment of Positive Symptoms (SAPS) scores for hallucinations, delusions, bizarre behaviour and formal thought disorder, and the Scale for the Assessment of Negative Symptoms (SANS) score for avolition/apathy.

Conclusion. The prevalence of cannabis use/abuse in this study was high, and our findings were comparable with those of previous international studies. Abuse/use started mainly in the teenage years, was more prevalent among males than females, and was associated with negative overall outcomes. There was also a positive correlation between cannabis and nicotine and alcohol use/abuse. Determination of cannabis abuse based solely on history was found to be reliable, and urine cannabis testing appeared to be of limited value in routine management of this group of schizophrenic patients.
Substance abuse and/or dependence are common problems among the general population, and evidence indicates that the incidence is even higher in individuals with mental health problems. In 2007, the US Substance Abuse and Mental Health Services Administration reported that, of the 24.9 million adults found to have a severe mental illness, $27.2 \%$ had used an illicit substance within the past year, and $22.3 \%$ met abuse or dependence criteria. Comparative figures for individuals without a severe mental illness were much lower, at $12.3 \%$ and $7.7 \%$ respectively.' Cannabis is currently the world's foremost illicit substance consumed - the United Nations estimates that it is used by $3.9 \%$ of the world's adult population. ${ }^{2}$

Co-morbid substance abuse is a confirmed risk factor for poorer symptomatic and functional outcomes in individuals with mental illness. ${ }^{3,4}$ Furthermore, service costs for individuals with, for example, a dual diagnosis of schizophrenia and substance abuse, can be twice that for patients without such diagnoses.

The rate of co-morbid cannabis consumption in individuals with schizophrenia is reportedly high. In their review of 53 clinical studies, Green et al. found that the lifetime prevalence of cannabis use was $42.2 \%$, and of cannabis misuse, $22.5 \%{ }^{\circ} \mathrm{A}$ number of correlates and risk factors predicting substance use in schizophrenia populations have emerged with some consistency. These include being unmarried, being male, and having lower educational levels, a childhood conduct disorder or a co-morbid antisocial personality disorder. 3,79

Although research on the effects of cannabis abuse on clinical parameters in individuals with schizophrenia has produced conflicting results, two prospective studies attempting to examine the longer-term outcome of cannabis use in this illness have both demonstrated poorer outcome and increased intensity of positive symptoms. ${ }^{10,11}$ A number of prospective epidemiological studies also now provide support for the hypothesis that cannabis abuse increases the subsequent risk for developing schizophrenia. ${ }^{12-14}$

In South Africa, the exact prevalence of cannabis use/abuse among the general population, as well as among individuals with mental disorders, has not been formally studied, but it is generally believed to be high. Peltzer and Ramlagan recently reviewed cannabis use trends (over a period of 12 years) in the South African population, by sourcing data from surveys, 
specialised alcohol and drug treatment centres, cannabis-related trauma unit admissions, and arrestee studies. ${ }^{15}$ They concluded that cannabis was the most common illicit substance used, with current self-reported cannabis use of 5 - 10\% among adolescents and $2 \%$ among adults. Furthermore, it was higher among men than women, higher in urban than rural areas, higher in the urban provinces of Western Cape and Gauteng than the other provinces, and higher among coloureds and whites than other racial groups.

Currently, no structured data exist for co-morbid cannabis use/ abuse in a South African schizophrenia population. However, some data have been reported, including a $46 \%$ lifetime prevalence of cannabis abuse in a study of HIV/AIDS riskbehaviour in a sample of 102 outpatients. ${ }^{16}$ Another study looking at risk factors for violence in a schizophrenic inpatient population, showed lifetime cannabis abuse to be $33 \%$ in the violent sample, and $27 \%$ in the non-violent sample. ${ }^{17}$

In view of the paucity of existing data, the purpose of this study was therefore to try to identify the demographic and clinical correlates of cannabis abuse in a large South African schizophrenia group. To limit confounding factors, a decision was made to use an ethnically homogeneous population.

\section{Methods}

From 2002 to 2005, participants were recruited from inpatient units and outpatient community clinics in the larger Cape Town metropole as part of an ongoing genetic study. Inclusion criteria were: (i) a diagnosis of schizophrenia according to DSM-IV-TR criteria: and (ii) Xhosa ethnicity (with 4/4 grandparents reported to be Xhosa). Men and women aged 18 - 65 years at all stages of illness were included.

All participants were interviewed by a trained psychiatrist and/or a Xhosa psychiatric nurse with extensive clinical experience, using a standardised interview - the Diagnostic Interview for Genetic Studies (DIGS) Version 2.0, which includes the Scales for the Assessment of Positive (SAPS) and Negative Symptoms (SANS). ${ }^{18}$ Both the SANS and the SAPS have subscales, with scores from 0 to 5 possible for each subscale. The Abnormal Involuntary Movement Scale (AIMS) was also completed for each participant. ${ }^{19}$

Interviews were supplemented by hospital/clinic chart records and collateral information from family members, where available. Patients were also questioned on their use of substances of abuse, and a urinary drug screen was performed on all participants. Use/abuse of cannabis was defined as using cannabis more than 21 times in a single year, based on the DIGS criteria. The urinary drug screen was specific for detecting cannabis use in the last 30 days. The test strip used was the One Step Marijuana Test Strip produced by Acon Laboratories, which has high sensitivity and specificity.

For the purposes of this study, the following demographic and clinical correlates were retrospectively investigated: cannabis use/abuse, age at start of cannabis use/abuse, duration of cannabis use/abuse, age, gender, marital status, level of education, employment status, smoking status, and alcohol abuse and dependence.

For the purposes of statistical analysis, patients were divided into two groups: (i) cannabis users/abusers; and (ii) non-cannabis users/abusers. Descriptive and comparative study analyses between the two groups were performed using independent Student's Ftests and chi-squared tests. The statistical package used was Microsoft Excel with WinStat.

All patients provided written informed consent, and the ethical guidelines as stipulated by the Committee for Human Research of Stellenbosch University were strictly adhered to.

\section{Results}

\section{Demographic variables}

The original study recruited 547 participants, of whom 52 were excluded owing to insufficient data regarding their history of cannabis use/abuse. Based on a history of use/abuse and/or positive urine test, 245 participants were grouped as cannabis users/abusers (CUA); this group included one participant who denied cannabis use/abuse but who tested positive on urine cannabis testing. Two hundred and fifty participants were grouped as non-cannabis users/abusers (NCUA).

The study group consisted of 410 male and 85 female participants, with an overwhelming majority of males $198.8 \%$; $N=242$ ) among the CUAs. Among the NCUAs, 67.2\% (N=168) were male and $32.8 \%(N=82)$ were female. The gender distribution difference between the two groups was statistically significant $(p<0.0001)$. Table I shows additional demographic variables.

\section{Illness variables}

Table II summarises the illness variables.

\section{Substance variables}

The current prevalence rate of cannabis use/abuse for the whole sample was $49.5 \%$. Ninety-five participants (CUA=94, $\mathrm{NCUA}=1$ ) had a positive cannabis urinary drug screen on interview. The screen revealed no positive tests for any of the other drugs of abuse Imethamphetamine, opiates, cocaine, 
methaqualone). On interview, 17 participants admitted to lifetime methaqualone use, and one each to cocaine and opiates.

The mean age at start of cannabis use/abuse was 20.2 years ISD 7.36, range 9 - 52). Data on the length of time that participants used/abused cannabis were available for only $41.2 \%$ (N=103) participants. Of these, 40.2\% (N=39) had used/abused cannabis for $\leq 1$ year, $6.2 \%(N=6)$ for between 1 and 2 years,

\begin{tabular}{|c|c|c|c|}
\hline & CUA & NCUA & p-value \\
\hline Age at interview (yrs) & $\begin{array}{l}37 \text { (SD } \\
9.63 \\
\text { range } \\
15-70)\end{array}$ & $\begin{array}{l}33(S D \\
11.88 \\
\text { range } \\
17-64)\end{array}$ & NS \\
\hline \multicolumn{4}{|l|}{ Marital status (N) } \\
\hline Divorced & 6 & \multirow{3}{*}{8} & NS \\
\hline Married & 11 & & $*<0.001$ \\
\hline Separated & 7 & & NS \\
\hline Single & 218 & 43 & $*<0.001$ \\
\hline Widowed & 2 & \multirow{2}{*}{$\begin{array}{r}13 \\
174\end{array}$} & NS \\
\hline Missing data & 1 & & NS \\
\hline Employment status (N) & & \multicolumn{2}{|l|}{3} \\
\hline Disability & 150 & 169 & NS \\
\hline Employed & 8 & 8 & NS \\
\hline Unemployed & 85 & 70 & NS \\
\hline Missing data & 2 & 3 & NS \\
\hline Education (N) & \multicolumn{3}{|c|}{18} \\
\hline No schooling & 4 & 60 & NS \\
\hline$<$ Grade 7 & 58 & 70 & NS \\
\hline Grade 7 & 91 & 53 & NS \\
\hline Grade 10 & 52 & \multirow{4}{*}{$\begin{array}{r}39 \\
4 \\
2 \\
4\end{array}$} & NS \\
\hline \multirow{3}{*}{$\begin{array}{l}\text { Grade } 12 \\
\text { Trade/apprentice- } \\
\text { ship } \\
\text { Diploma }\end{array}$} & 36 & & NS \\
\hline & 1 & & NS \\
\hline & 1 & & NS \\
\hline Missing data & 2 & & NS \\
\hline *Significance at $p<005$ level. & & & \\
\hline
\end{tabular}

7.2\% (N=7) for between 2 and 3 years, and $52.5 \%(\mathrm{~N}=51)$ for $\geq 4$ years. Table III presents additional substance variables.

\section{Clinical variables}

Statistically significant differences between the two groups could be documented for all of the positive symptom subscores as recorded on the SAPS. With reference to negative symptom subscores as recorded on the SANS, the only difference reported was that for the avolition/apathy subscale, with significantly higher scores for the CUA group ( $p<0.0001)$. Table IV presents full clinical variables.

\section{Discussion}

The overall lifetime prevalence of cannabis use/abuse in our study was $49.49 \%$, which was comparable to the mean $42.2 \%$ lifetime prevalence of cannabis use (range 19 - 89\%) reported by Green et al. in their review of 53 treatment samples. ${ }^{6}$

Of particular note was the apparent reliability of participants' responses with reference to their use/abuse status. Only one participant denied any use/abuse on history and was subsequently found to test positive on urine screen. A 'no' therefore represented a strong negative predictor of cannabis use/abuse. Of the group who admitted to be positive for cannabis use/abuse, only 94 (38.3\%) were confirmed positive on urine testing. Taking into account that (i) having a history of cannabis use/abuse does not mean that one is currently using/abusing cannabis; and (ii) our group was heterogeneous in terms of hospitalisation status, this was not an unexpected finding. Therefore, our findings raise the question of the value of actual testing ( $v$. only taking a history) for cannabis use/abuse in our setting, taking into account our severely financially constrained health system.

Our dataset replicated previous findings about associations between cannabis use/abuse and male gender, single status and increased rates of relapses and hospitalisations. ${ }^{3,7-9}$ In contrast, employment status and educational levels were not found to be correlates for cannabis use/abuse; ;,20 however, this could have been influenced by the overall low level of formal employment for our total sample which, unfortunately, was in keeping with a high

Table II. Comparison of illness variables between CUA and NCUA groups

\begin{tabular}{llll}
\multicolumn{4}{l}{ Table II. Comparison of illness variables between CUA and NCUA groups } \\
\hline \multicolumn{1}{c}{ CUA } & \multicolumn{1}{c}{ NCUA } & p-value \\
\hline Age at onset of symptoms & 21.2 (SD 4.51, range 11 - 38) & 25.3 (SD 8.16, range 10 - 55) & $*<0.0001$ \\
Mean number of hospitalisations & 3.8 (SD 4.49, range 0 - 21) & 2.9 (SD 3.23, range 0 - 16) & $*<0.001$ \\
Mean number of relapses & 4 (SD 4.80, range 1 - 21) & 3.1 (SD 2.97, range 0 - 11) & $*<0.001$ \\
*Significance at $p<0$ 05 level. & & & \\
\hline
\end{tabular}




\begin{tabular}{|c|c|c|c|}
\hline & $\begin{array}{l}\text { CUA } \\
(N)\end{array}$ & $\begin{array}{l}\text { NCUA } \\
\text { (N) }\end{array}$ & p-value \\
\hline Alcohol abuse & 81 & 29 & $*<0.001$ \\
\hline Alcohol dependence & 4 & 3 & NS \\
\hline Nicotine use & 232 & 136 & $*<0.0001$ \\
\hline *Significance at $p<005$ level. & & & \\
\hline
\end{tabular}

Table IV. Comparison between CUA and NCAU groups with reference to SAPS and SANS subscores and AIMS total score

\begin{tabular}{|c|c|c|c|}
\hline & Mean & SD & $p$-value \\
\hline \multicolumn{4}{|c|}{ Affective flattening/blunting } \\
\hline NCUA & 2.21 & 1.2 & \multirow{3}{*}{00785} \\
\hline CUA & 2.40 & 1.2 & \\
\hline Total & 2.31 & 1.2 & \\
\hline \multicolumn{4}{|l|}{ Alogia } \\
\hline NCUA & 1.57 & 1.50 & \multirow{3}{*}{0.1264} \\
\hline CUA & 1.78 & 1.47 & \\
\hline Total & 1.67 & 1.5 & \\
\hline \multicolumn{4}{|c|}{ Avolition/apathy } \\
\hline NCUA & 2.25 & 1.13 & \multirow{3}{*}{$* 0.0038$} \\
\hline CUA & 2.54 & 1.08 & \\
\hline Total & 2.39 & 1.1 & \\
\hline \multicolumn{4}{|c|}{ Anhedonia/asociality } \\
\hline NCUA & 2.60 & 0.99 & \multirow{3}{*}{0.1892} \\
\hline CUA & 2.72 & 1.05 & \\
\hline Total & 2.66 & 1.0 & \\
\hline \multicolumn{4}{|l|}{ Attention } \\
\hline NCUA & 0.56 & 1.10 & \multirow{3}{*}{00842} \\
\hline CUA & 0.74 & 1.22 & \\
\hline Total & 0.65 & 1.2 & \\
\hline \multicolumn{4}{|c|}{ Hallucinations } \\
\hline NCUA & 1.68 & 1.68 & \multirow{3}{*}{ *0.0199 } \\
\hline CUA & 2.03 & 1.62 & \\
\hline Total & 1.86 & 1.7 & \\
\hline \multicolumn{4}{|l|}{ Delusions } \\
\hline NCUA & 1.66 & 1.58 & \multirow{3}{*}{$* 0.0053$} \\
\hline CUA & 2.07 & 1.63 & \\
\hline Total & 1.87 & 1.6 & \\
\hline \multicolumn{4}{|c|}{ Bizarre behaviour } \\
\hline NCUA & 1.08 & 1.46 & \multirow{3}{*}{$* 0.0001$} \\
\hline CUA & 1.71 & 1.59 & \\
\hline Total & 1.39 & 1.6 & \\
\hline \multicolumn{4}{|c|}{ Formal thought disorder } \\
\hline NCUA & 1.02 & 1.38 & \multirow{3}{*}{$* 0.0014$} \\
\hline CUA & 1.46 & 1.58 & \\
\hline Total & 1.24 & 1.5 & \\
\hline \multicolumn{4}{|l|}{ AIMS } \\
\hline NCUA & 1.34 & 3.61 & \multirow{3}{*}{08604} \\
\hline CUA & 1.28 & 3.41 & \\
\hline Total & 1.31 & 3.5 & \\
\hline Significance & & & \\
\hline
\end{tabular}

national unemployment rate. Also deeply worrying was that a third of the participants who were unemployed were not receiving a social grant.

As demonstrated previously in the literature, our study group also showed a lower mean age of onset of illness in the cannabis use/ abuse group.? Three possible mechanisms have been suggested in the literature to explain this finding: Firstly, it is possible that cannabis has no influence on risk or age at onset, and that younger patients, compared with older patients, are more likely to use this substance before the first psychotic episode because its use is also age-related. ${ }^{21}$ Secondly, cannabis use could hasten the onset of psychosis in individuals who would have developed this disorder even if they had never used the substance; this notion is supported by evidence suggesting that cannabis may trigger or exacerbate psychotic symptoms in healthy individuals and schizophrenic patients. ${ }^{22}$ A third suggested mechanism is that cannabis lowers the threshold for developing schizophrenia in those genetically at risk for developing it. It is known that the enzyme catechol-O-methyltransferase (COMT) plays an essential role in the breakdown of dopamine in the prefrontal cortex. Caspi et al. has shown that COMT moderates the influence of adolescent cannabis use, with at least a fivefold increased risk of developing schizophreniform disorder in cannabis users homozygous for the high activity Val allele. In contrast, homozygosity for the Met allele offered relative protection (odds ratio 1.1), whereas the risk for heterozygotes was intermediate (odds ratio 2.5). ${ }^{23}$

Both nicotine and alcohol use/abuse were common in our entire sample, but there were almost twice the number of nicotine users, and three times the number of alcohol abusers, in the cannabis use/abuse group. Overall, there was a $22.4 \%$ lifetime prevalence of alcohol abuse in the total sample of 547 , which is almost twice the $11.4 \%$ lifetime prevalence rate of alcohol abuse recently reported for the general South African population. ${ }^{24}$ Very few other substances of abuse were reported in our sample, which is similar to findings of other previously reported South African schizophrenia samples. 17,25

The absence of methamphetamine use/abuse in our sample, in view of the current high prevalence rates of methamphetamine use/abuse in the Western Cape, is notable. ${ }^{26}$ Possible explanations for this could be that it only appeared to become a popular drug of abuse towards the end of 2004, and our sample of patients was assessed between 2002 and 2005. Secondly, cannabis has for generations been regarded as a traditional drug among the indigenous southern African populations, and its use has therefore possibly been associated with low moral blameworthiness. ${ }^{27}$ Thirdly, the relatively higher 
costs of methamphetamines might have made cannabis a more favourable option.

In keeping with previous data, cannabis use/abuse was shown to be associated with a significantly increased prevalence of positive symptoms that included hallucinations, delusions, formal thought disorder and bizarre behaviour., ${ }^{30,11}$ However, it should be noted that more of the cannabis use/abuse group were inpatients at the time of the assessment, although the difference between the two groups was not statistically significant.

In our study, the mean AIMS score was lower (but not statistically significant) for the cannabis use/abuse group. These findings were expected as this sample overlapped with that reported on by Niehaus et al. whose results suggest that cannabis abuse might be protective against involuntary movements. ${ }^{28}$ MullerVahl proposed that tetrahydrocannabinol (THC) protects against movement disorders by stimulating release of dopamine from dopaminergic projections from the substantia nigra ending in the striatum. ${ }^{29}$ It is known that deficiencies of this pathway may cause movement disorders.

Possible limitations of this study included the following: (i) assessment instruments were not translated into Xhosa; (ii) the assessment relied on historical information with possible recall bias; and (iii) the group sample was mixed with regard to hospitalisation status and, therefore, stage of illness.

Strengths of this study included the use of (i) a large, ethnically homogeneous population; (ii) validated structured clinical interviews; and (iii) multiple sources of information.

\section{Conclusion}

The prevalence of cannabis use/abuse in our study population was found to be significant and comparable with previous international studies. Cannabis use/abuse started mainly in the teenage years, was more prevalent among males and was found to have a negative association with outcome, in terms of the degree of symptomatology as well as rates of hospitalisations and relapses. The prevalence of co-morbid alcohol and nicotine abuse was also found to have a positive correlation with cannabis use/abuse. Taken together, our findings underscore the clear need for a targeted dual diagnosis service to improve outcomes for our clients. Finally, our study results also seem to suggest that the practice of urine cannabis testing appears to add little value in routine management of known schizophrenic patients. A thorough interview with reliable collateral information would seem to be sufficient to exclude substance abuse in the majority of such cases.

\section{References}

1. Department of Health and Human Services: Substance Abuse and Mental Health Services Administration Office. Results from the 2006 National Survey on Drug Use and Health: National Findings. Rockville, MD, USA: SAMHSA, Office of Applied Studies, 2007

2. United Nations Office on Drugs and Crime. 2008 World Drug Report. Vienna United Nations, 2008

3. Faris C, Brems C, Johnson M, Wells R, Burns R, Kletti N. A comparison of schizophrenic patients with or without coexisting substance use disorder. Psychiatric Quarterly 2003; 74: 205-222.

4. Kovasznay B, Fleischer J, Tanenberg-Karant M, Jandorf L, Miller A, Bromet E. Substance use disorder and the early course of illness in schizophrenia and affective psychosis. Schizophr Bull 1997; 23: 195-201

5. Bartels S, Teague G, Drake R, Clark R, Bush P, Noordsy D. Service utilization and costs associated with substance use among rural schizophrenic patients. J Nerv Ment Dis 1993; 181: 227-232

6. Green B, Young R, Kavanagh D. Cannabis use and misuse prevalence among people with psychosis. BrJ Psychiatry 2005; 187: 306-313

7. Salyers $M$, Mueser K. Social functioning, psychopathology and medication side effects in relation to substance use and abuse in schizophrenia. Schizophr Res 2001 48: 109-123.

8. Swartz $M$, Wagner $H$, Swanson J, et al. Substance use in persons with Schizophrenia: Baseline prevalence and correlates from the NIMH CATIE Study. J Nerv Ment Dis 2006; 194: 164-172.

9. Mueser K, Drake R, Ackerson T, Alterman A, Miles K, Noordsy D. Antisocial personality disorder, conduct disorder, and substance abuse in schizophrenia. J Abnorm Psychol 1997; 106: 473-477

10. Caspari D. Cannabis and schizophrenia: results of a follow up study. Eur Arch Psychiatry Clin Neurosci 1999; 249: 45-49.

1 1. Buhler B, Hambrecht M, Loffler W, Van der Heiden W, Hafner H. Precipitation and determination of the course and onset of schizophrenia by substance abuse - a retrospective and prospective study of 232 population-based first illness episodes. Schizophr Res 2002; 54: 243-251.

12. Andreasson S, Allebeck P, Engstrom A, Rydberg U. Cannabis and schizophrenia: a longitudinal study of Swedish conscripts. Lancet 1987; 2: 1483-1486.

13. Van Os J, Bak M, Hanssen M, Biil R, de Graaf R, Verdoux H. Cannabis use and psychosis: a longitudinal population-based study. Am J Epidemiol 2002; 156: 319 327

14. Arseneault $L$, Cannon M Witton I. Murray R. Causal association between cannabis and psychosis: Examination of the evidence. BrJ Psychiatry 2004; 184: $110-117$.

15. Peltzer K, Ramlagan S. Cannabis use trends in South Africa. South African Journal of Psychiatry 2007; 13(4): 126-131

16. Koen L, Uys S, Niehaus D, Emsley R. Negative symptoms and HIV/AIDS risk behavior in schizophrenia. Psychosomatics 2007; 48: 128-134

17. Koen L, Kinnear C, Corfield V, et al. Violence in male patients with schizophrenia: risk markers in a South African population. Aust N ZJ Psychiatry 2004; 38: 254-259.

18. Nurnberger J, Blehar $M$, Kaufmann $C$, et al. Diagnostic interview for genetic studies. Rationale, unique features and training. NIMH Genetics Initiative. Arch Gen Psychiatry 1994; $51: 849-859$

19. Guy W. ECDEU Assessment Manual for Psychopharmacology, revised. Rockville, MD, USA: National Institute of Mental Health, 1976: 534-537.

20. Kavanagh D, Waghorn $G$, Jenner L, et al. Demographic and clinical correlates of comorbid substance use disorders in psychosis: multivariate analyses from an epidemiological sample. Schizophr Res 2004; 66: 11 5-124.

21. Veen N, Selton J, Van der Tweel, I, Fella W, Hoek H, Kahn R. Cannabis use and age at onset of schizophrenia. Am J Psychiatry 2004; 161: 501-506.

22. Linszen $D$, Dingemans $P$, Lenior $M$. Cannabis abuse and the course of recent onset schizophrenia disorders. Arch Gen Psychiatry 1994; 51 : 273-279.

23. Caspi A, Moffitt $T$, Cannon M et al. Moderation of the affect of adolescent-onset cannabis use on adult psychosis by a functional polymorphism in the catechol-O methyltransferase gene: Longitudinal evidence of a gene X environment interaction. Biol Psychiatry 2005; 57: $1117-1127$

24. South African Community Epidemiology Network on Drug Use. Alcohol and Drug Abuse Trends: Updates Jan 2002 - December 2006. Cape Town: Medical Research Council, November 2002 - May 2007

25. Niehaus $D$, Koen $L$, Laurent $C$, et al. Positive and negative symptoms in affected sib pairs with schizophrenia: Implications for genetic studies in an African Xhosa sample. Schizophr Res 2005; 79: 239-249.

26. Stein $D$, Seedat $S$, Herman $A$, et al. Lifetime prevalence of psychiatric disorders in South Africa. BrJ Psychiatry 2008; 192: $112-117$.

27. Gastrow P. Mind-blowing: The Cannabis Trade in Southern Africa. Cape Town: Institute for Security Studies, 2003

28. Niehaus DJH, Du Plessis $S$, Koen $L$, et al. Predictors of abnormal involuntary movement in an African schizophrenia population. I Neuropsychiatry Clin Neurosci 2008; 20(3): 317-326.

29. Muller-Vahl K. Cannabinoids reduce symptoms of Tourette's syndrome. Expert Opin Pharmacother 2003; 4: 1717-1725. 